\title{
ОБЩИЕ ПОЛОЖЕНИЯ ПО КОНСАЛТИНГУ В КОММЕРЧЕСКОЙ ДЕЯТЕЛЬНОСТИ (МАРКЕТИНГА). ИНФОРМАЦИОННЫЕ ТЕХНОЛОГИИ И КОНСАЛТИНГ
}

\author{
(c) 2019 Данелян Тэя Яновна \\ кандидат экономических наук, \\ доцент кафедры прикладной информатики и информационной безопасности \\ Российский экономический университет имени Г.В. Плеханова, Россия, Москва \\ E-mail: tdanelan@yandex.ru
}

В данной статье автор рассматривает необходимость внедрения информационных технологий в процесс консультации для увеличения эффективности работы консультирующего подразделения и, следовательно, производственного предприятия в целом.

Ключевые слова: производственное предприятие, консалтинг, маркетинг, информационная система, информационные технологии.

Производственное предприятие (ПП) - любое предприятие, производящее преобразование внешних ресурсов в общественные блага по рис. 1.

Здесь: N - природные ресурсы;

$\mathrm{C}$ - общественные блага

$\mathrm{F}$ - производственная функция

$\mathrm{R}$ - регулирующее устройство

ВC - внешняя среда

С тем, чтобы ПП, или, далее, экономический объект (Э.О.), работал надежно - с минимальным риском и максимальной прибылью,- необходимо анализировать процесс производства и результаты процесса производства.

Каждое предприятие - система с обратной связью и управлением производством: учет, контроль, анализ производственной деятельности ПП. Анализ деятельности ПП может выполняться как в финансовом, так и в материальном плане (выпуск продукции) с учетом воздействия внешней среды, т.е. рынка с его характеристика- ми (емкость, жизненный цикл товара, конкурентоспособность товара на рынке).

Анализ результатов деятельности Э.О. складывается из анализа способа функционирования Э.О., анализа реакции рынка и влияния внешней среды (экология, демография, политика) на поведение Э.О.

Результаты анализа лежат в основе процесса регулирования способом функционирования, т.е. в основе процесса принятия решения по работе предприятия.

Предприятие должно иметь подразделение, выдающее консультацию по производственной деятельности предприятия. Таким образом, процесс консультации - это деятельность, процедура, по выдаче рекомендаций менеджеру предприятия при принятии решений о внесении изменений в производственную функцию предприятия. Такое подразделение - службы маркетинга, где реализуется функция консалтинга.

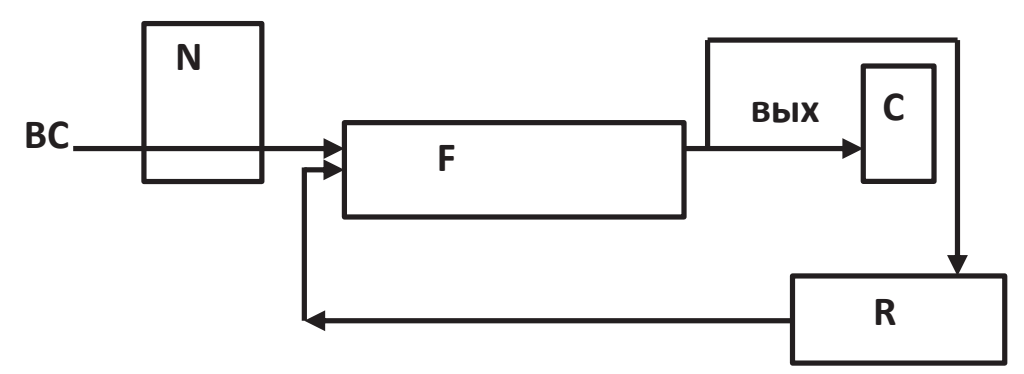

Рисунок 1 
Консалтинг (в общем смысле) имеет три вида:

1. по общеюридическим вопросам (правовой консалтинг) или консалтинг общего вида $\mathrm{K}^{0}$;

2. по конкретному виду деятельности (по производственной функции), т.е. проблемно-ориентированный или функциональный $\mathrm{K}^{\mathrm{F}}$;

3. по маркетингу $\mathrm{K}^{\mathrm{M}}$

Если на предприятии имеется отдел маркетинга, то отдел должен быть подчинен коммерческому директору. Маркетинг - это система управления производственной и сбытовой деятельностью экономического объекта, основанная на комплексном анализе рынка и направленная на решение проблем реализации продукта данного экономического объекта, в т.ч. путем целенаправленного формирования спроса на продукцию и услуги. Таким образом маркетинг выполняет систему мероприятий по изучению рынка, активному воздействию на потребительский спрос, систему планирования и воплощения замысла предприятия по выпуску продукции; планированию и воплощению ценообразования, а также систему мероприятий по получению консультаций по продвижению и реализации товаров и услуг, удовлетворяющих цели отдельных лиц и организаций и само ПП.

Консалтинг - одна из функций маркетинга, связанная с деятельностью по консультированию продуцентов, продавцов, покупателей по вопросам:

- деятельности предприятий

- оценки торгово-политических условий

- экспортно-импортных операций

- по оценке и разработке ТЭО на внедрение новых технологий и производств.

\section{Структура управления экономическим} объектом.

Для того чтобы предприятие работало согласно принятой технологии, необходимо активное управление и контроль предприятия.

Управление - процесс преобразования входной информации в выходную под непосредственным контролем и воздействием управляющего органа R (рис 2).

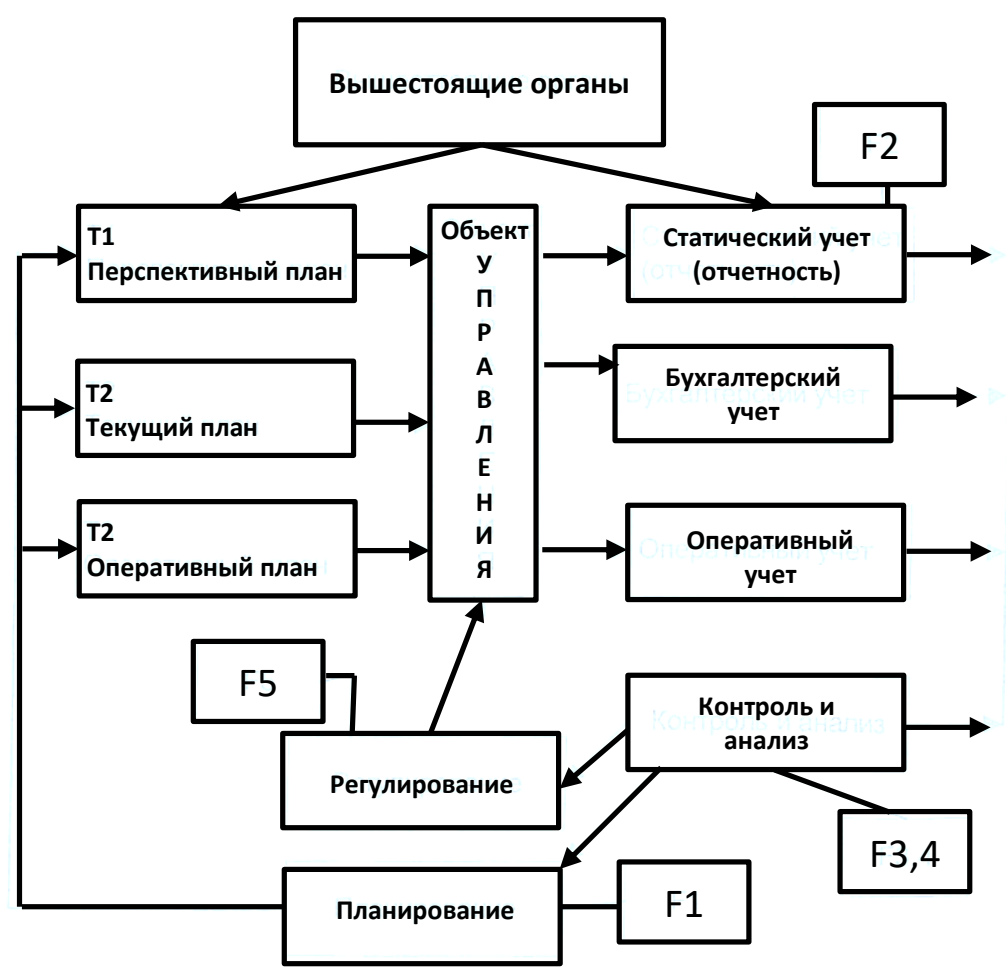

Рисунок 2. Структура управления экономическим объектом 


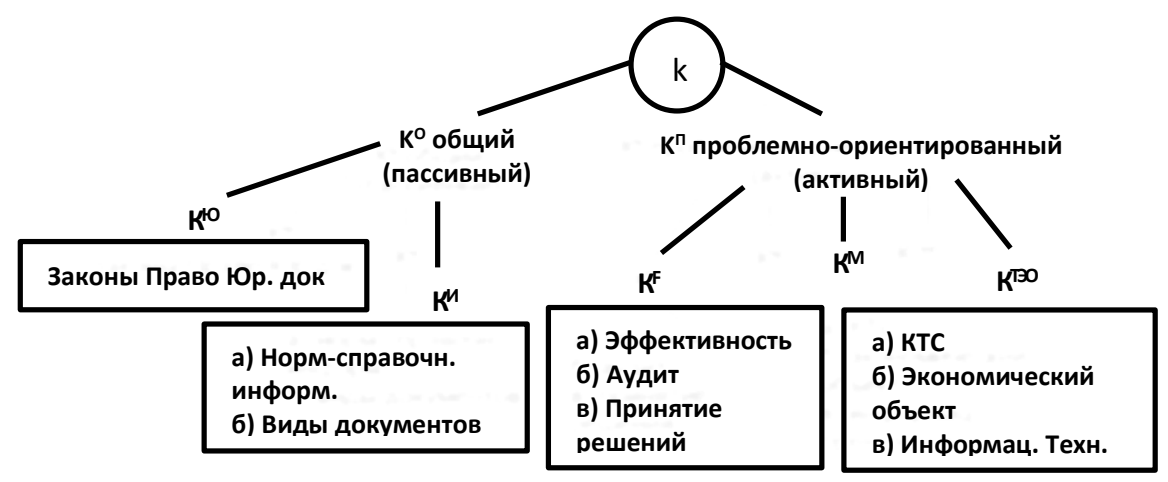

Рисунок 3. Классификация консалтинга

Виды консалтинга и информационные технологии (рис 3).

Здесь: $\mathrm{K}^{\mathrm{F}}-$ консалтинг по основным функциям управления Э.О.;

$\mathrm{K}^{И}$ - информационный консалтинг;

$\mathrm{K}^{Ю}$ - юридический консалтинг;

$\mathrm{K}^{\mathrm{M}}$ - маркетинговый консалтинг;

$\mathrm{K}^{\mathrm{T} Э О}$ - по технико-экономическому обоснованию;

К - область действия консалтинга;

$\mathrm{K}^{0}$ - говорит о том: что, где, когда, и какая требуется входная информация для принятия решения по управлению экономическим объектом. $\mathrm{K}^{И}$ - консалтинг для повышения оперативности получения справок, связанных со стандартными и нормативными документами, используемыми для управления Э.О.

Информатизация консалтинга общего типа $\mathrm{K}^{0}$ - это автоматизация получения справок консалтинга. Справки в режиме $\mathrm{K}^{И}$ и $\mathrm{K}^{\mathrm{TM}}$ могут выдаваться как в виде фактов, так и в виде документов. Правовая $\mathrm{K}^{10}$ - справка - это справка по правам и обязанностям. К - информационный консалтинг - это информационно-справочная система. Она выдает справку о наличии того или иного документа. Общий консалтинг всегда на уровне неавтоматизированного режима использовался для библиотек, архивов, нотариальных контор.

$\mathrm{K}^{\Pi}$ - дает рекомендации по улучшению функционирования экономического объекта как в финансовом, так и в экономическом плане. Эта рекомендация дается на уровне аудита. Она может быть принята, а может быть и нет. Помимо этого активный консалтинг касается основных функций деятельности, связанных с технико экономическим планированием, расчётом производственных мощностей, фонда основных средств оплаты труда, мат. ценностей и пр.

Помимо прямого анализа функций деятельности проблемно-ориентированный (активный) $\mathrm{K}^{\mathrm{a}}$ консалтинг может давать рекомендации на перспективу, используя рекомендации имитационно-статистического моделирования родственных экономических объектов.

$\mathrm{K}^{\mathrm{M}}$ - консалтинг по маркетингу нуждается в получении информации по мат. стат. моделям о способах рекламы и связях с рынком.

$\mathrm{K}^{\mathrm{T}}$ - консалтинг используют с тем, чтобы определить устойчивость, надежность, риски и эффективность работы предприятия в целом.

Историческая справка.

Увеличение объемов информации и появление новых нормативов, регламентирующих деятельность экономических объектов, потребовало автоматизации введения новых информационных технологий. Такими технологиями стали информационно-поисковые справочные системы (ИПС и ИСС).

ИПС - информационно поисковая система - это совокупность языковых, технических и алгоритмических средств, предназначенных для хранения, поиска и выдачи информации.

ИСС - информационно-справочная система - это система регистрации фактов, переработки и хранения информации, предназначенной для обеспечения абонентов сведениями справочного характера.

ИСС это разновидность ИПС, т.е. ИПС которая обеспечивает выдачу ответов на информационные запросы, касающиеся интересующих потребителей актов. Запрос и ответ называются фактографическими.

ИПС - документальные предназначены для 


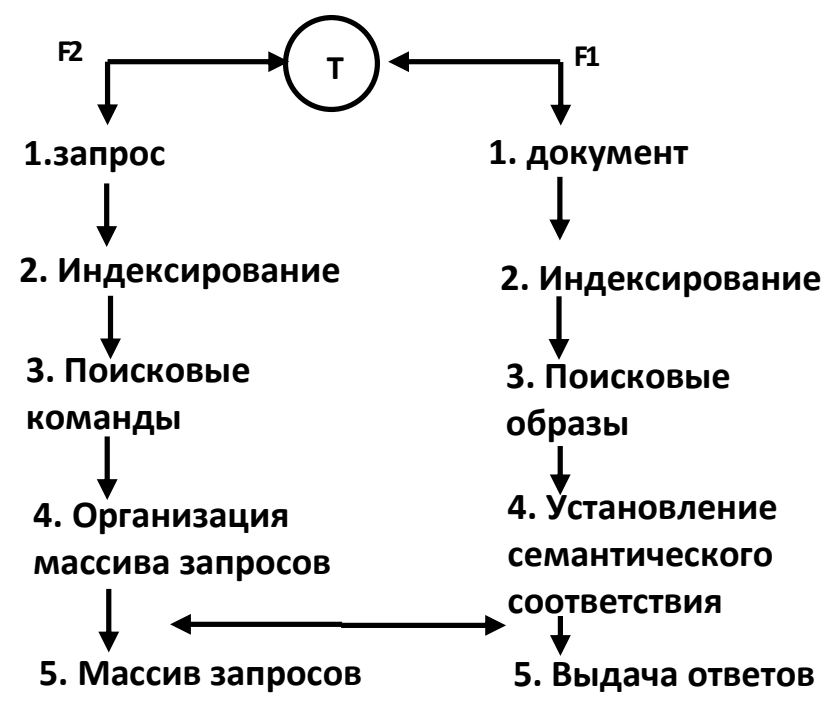

Рисунок 4

отыскивания документов, статей, отчетов и пр.

Информационно поисковые и справочные системы реализуют два вида функций:

F1 - выдача ответа - информация об объектах и знаниях, отображенная в документах и образующая информационные массивы ответов.

F2 - организация запроса - информация, отражающая информационную потребность пользователя, которая называется запросам, (рис. 4)

Здесь: Т - Тезаурус, организованный специальным образом словарь, используемый в ИПС и в ИСС при поиске информации. Он отражает семантические связи между словами или другими смысловыми объектами данного языка, или систему сведений (представлений) о внеязыковых объектах.

F1 - это система, реализующая ответ по запросу F2 это связь между абонентом и системой через запрос. Вместе F1 и F2 это информационный консалтинг общего типа. Информационные технологии, используемые для автоматизации консалтинга или системы информационного консалтинга определяются:

1. Режимами эксплуатации (централизованный и децентрализованный)

2. Режимами работы (диалоговый и пакетный)

3. Методами организации работы (сетевой и индивидуальный)

4. Обеспечением:

- программным (станд. ППП и оригин. ППП);
- техническим (ПЭВМ, сети, АРМ);

- информационным (способы и средства хранения и ведения информации);

- другое (правовое и юридическое, лингвистическое и административное);

Информационные технологии консалтинга проблемно-ориентированного (ПОК) и общего типа.

Исходя из направленности проблемно-ориентированного консалтинга (ПОК) основные его функции:

- Давать оценку функциональной деятельности объекта; способам получения прибыли; затратам;

- Давать оценку устойчивым состояниям объекта, исходя из анализа финансово-экономической деятельности объекта для принятия решений по управлению функционированием объекта;

- Давать оценку структурно-функциональную и затратную новым проектам, разработкам, чтобы принять решение о целесообразности этих разработок в смысле их приобретения и внедрения.

Исходя из функций, ПОК при своей организации должен использовать экономико-математические модели для моделирования процесса функционирования объекта, определения результатов его деятельности на максимум и минимум при различных ситуациях.

С помощью математических моделей можно описывать процессы прогнозирования, роста 
прибыли, межотраслевых балансов и т.п. Таким образом, одним из инструментов ПОК должны быть средства экономического, имитационного, математического и статистического моделирования.

Математическое моделирование - процесс построения математических моделей, адекватно отражающих процессы и явления внешней среды. Так как они описывают объект в статике, а процесс по которому нужно получить консультацию наблюдается во времени, то применяют математические модели имитационного моделирования (со временем $\mathrm{t}$ ).

Имитационное моделирование - изучение процессов, происходящих в системе, с искусственной имитацией случайных величин, от которых зависят эти процессы. Они комбинируют детерминированные и стохастические зависимости, влияющие на работу и функционирования в целом ЭО.

Для анализа устойчивости и рискованности функционирования ЭО, ПОК использует методы статистического моделирования, с помощью которых устанавливается зависимость между факторами, влияющими на результат работы системы. Используются также методы регрессионного, факторного анализа.

Если факторы случайны, то используют вероятностную систему моделей. В технологии ПОК должны существовать средства, позволяющие оценивать структуру экономической системы. Ее оценивают через показатели, вычисленные с помощью расчетных формул. Из полученных результатов с помощью метода экспертных оценок выделяют те показатели, которые важны для деятельности экономического объекта такие как: надежность, сложность, качество управления, качество функционирования, иерархичность, пропускная способность, универсальность, информативность. В результате консалтинг дает совет по принятию решений об изменении структуры экономической системы. Кроме того, необходимо использовать экономико-математический аппарат, способный анализировать влияние внешней среды на деятельность ЭО: отслеживать качество товара, оценивать жизненный цикл товара на конкретном рынке, емкость рынка по данному товару, конкурентоспособность товарами т.п.

Таким образом при организации работы ПОК его функциональное обеспечение включает экономико-математические методы (ЭММ), программное обеспечение (ПО), техническое, лингвистическое, технологическое и документальное.

$\mathrm{K}^{\Pi}:$ ФО ::= (ЭММ = (MМ, ИМ, СМ, M, МАР, ЭО, ЭМM $)+\Pi О::(Э \mathrm{MM}=(\Pi \Pi \Pi / \mathrm{Op}))+\mathrm{TO}::=(\mathrm{KTC}=$ (ПЭВМ; орг.связь; терминалы) $)+$ ЛО + АО + ЮО + ТО + ДО: (техническое задание; технический проект, инструкции пользователю)

Чтобы реализовать информационный консалтинг, используют: АРМ технологии, кейс-технологии, средства сетевых технологий.

АРМ технология ориентирована на конкретную проблему и конкретное рабочее место.

Сетевая технология - это специальным образом построенная взаимосвязь между ЭВМ (или АРМами) так, что пользователь может обращаться к одним и тем же данным, хранимым централизованно и используемым распределение.

Кейс-технологии - это вычислительно-ориентированные технологии. Они позволяют решить вопрос консультанта по новой структуре информационного и функционального обеспечения экономического объекта.

Рассмотрим пример проблемно-ориентированного консалтинга Кп, воплощённого в системе СДКМС. СДКМС - это система декомпозиции (анализ), композиции (синтез) и модификации сложных систем. В СДКМС используются кейс-технологии. Т.к. кейс-технологии без АРМ технологий реализуются очень неудобно, то в СДКМС они работает в интерактивном режиме. В этом режиме работают АРМ-технологии.

Аспекты использования СДКМС:

- определять прибыльность ЭО

- давать структурную оценку ЭО на уровне оценочных и экспертных характеристик.

Результаты оценок хранятся в рекламном каталоге, который дополняется аттестационными характеристиками изучаемого объекта. Рекламный каталог используется для рекламы объекта, выдачи консультаций при выборе решения, в работе брокера.

СДКМС строит графическое изображение структуры объекта, выдавая эту структуру на экран со спецификацией элементов и связей объекта. На рис. 5 представлены схема взаимодействия модулей СДКМС и схема данных.

Система работает в режиме коллективного пользования. При активизации режима ввода (1) со специального бланка вводятся данные в файл связи $£ 2$ и в файл перечня элементов $\mathrm{f} 1$. Эта база 


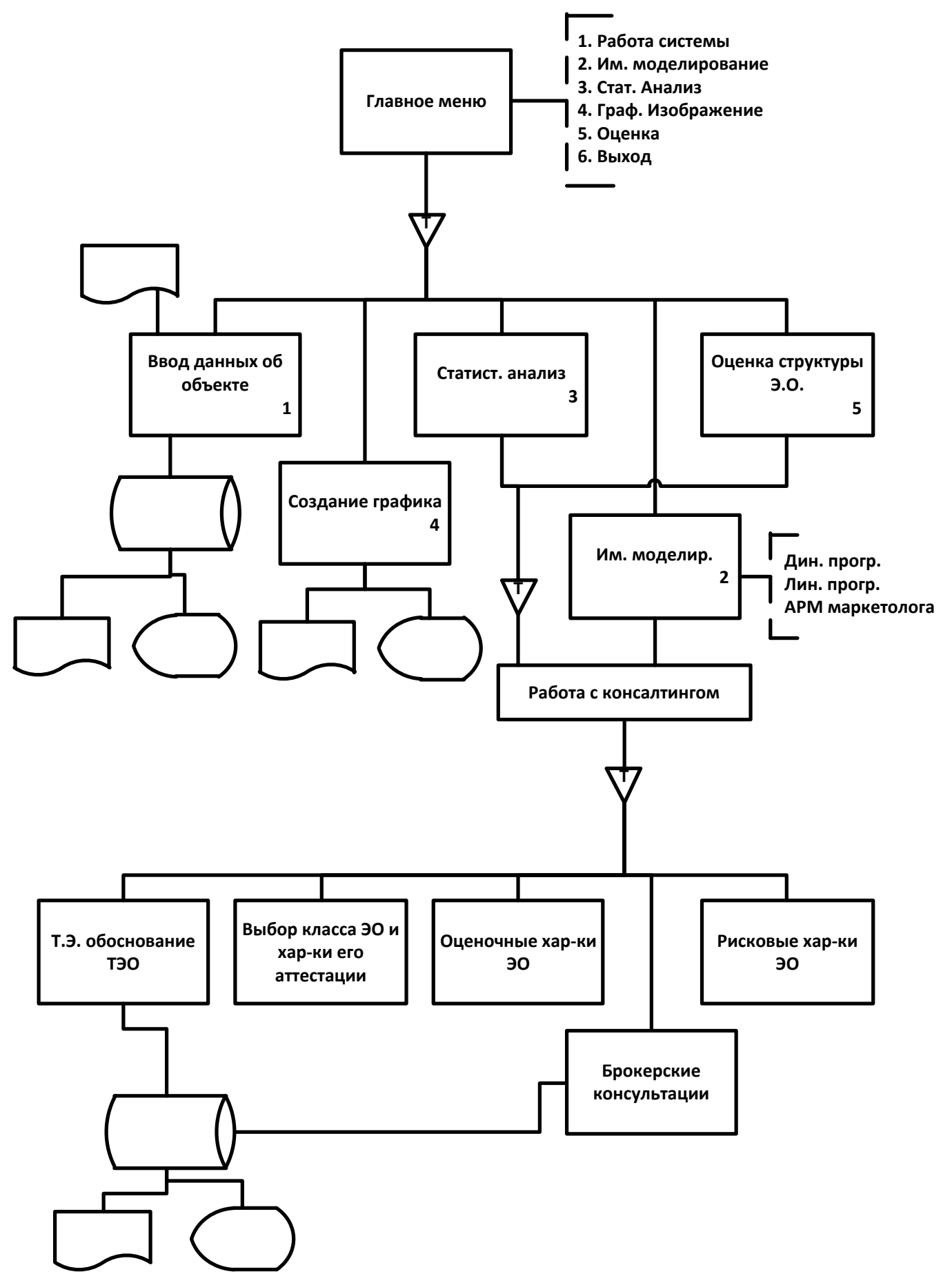

Рисунок 5. Схема взаимодействия модулей 
знаний об ЭО хранится в БД на сервере. Эксперт, желая изучить систему, просматривает список экономических систем и вызывает конкретную систему на рабочую станцию. Возможны следующие действия:

1. Создание и модификация структуры системы для последующей оценки структурных характеристик, выдачи пользователю графического изображения системы для последующего внесения изменений.

2. Получение ответа на вопрос о повторяемости операций или о стандартности действий, чтобы определить (если система унифицирована) возможности использования НИТ (бл 3).

3. Получение оценки о значимости системы (бл 5).

4. Получение информации о количестве документов, связей, количестве обрабатываемой информации. Консультант обращается к блоку статистика (3).

Результат (3) используется для оценки системы по критериям:

$\mathrm{R}$ - «Надежность»

I - «информативность»

И - «универсальность»

$П-$ «пропускная способность»

$\mathrm{C}-$ «сложность» (блок 5)

Эксперт выделяет наиважнейшие характеристики, вычисляет усредненные экспертные оценки и получает вес данной системы по отношению к другим родственным системам данного класса.

Результаты оценки переносятся в рекламный каталог, чтобы накапливать знания о системax.

Т.к. структурные признаки не могут однозначно определить устойчивость, СДКМС позволяет проводить имитационное, статистическое и математическое моделирование данной экономической системе. Пример консалтинга общего типа $\mathrm{K}^{0}$ - это такие системы как «Консультант плюс», «Гарант», «Юсис». Эти системы реализуют получение ответов в следующих режимах.

Режим юридический:

указы, акты, постановления федерального и Московского значения.

Режим бухгалтерия (БУ):

состоит из двух под режимов:

1) вопросы и ответы по БУ и налогообложению,

2) нормативно-справочные документы.

Нормативные документы выдаются в виде:

1. Документальная часть

2. Фактографическая часть

3. Деловые бумаги (типовые формы)

В системах осуществляется поиск по тематикам, по датам. В системах обеспечивается

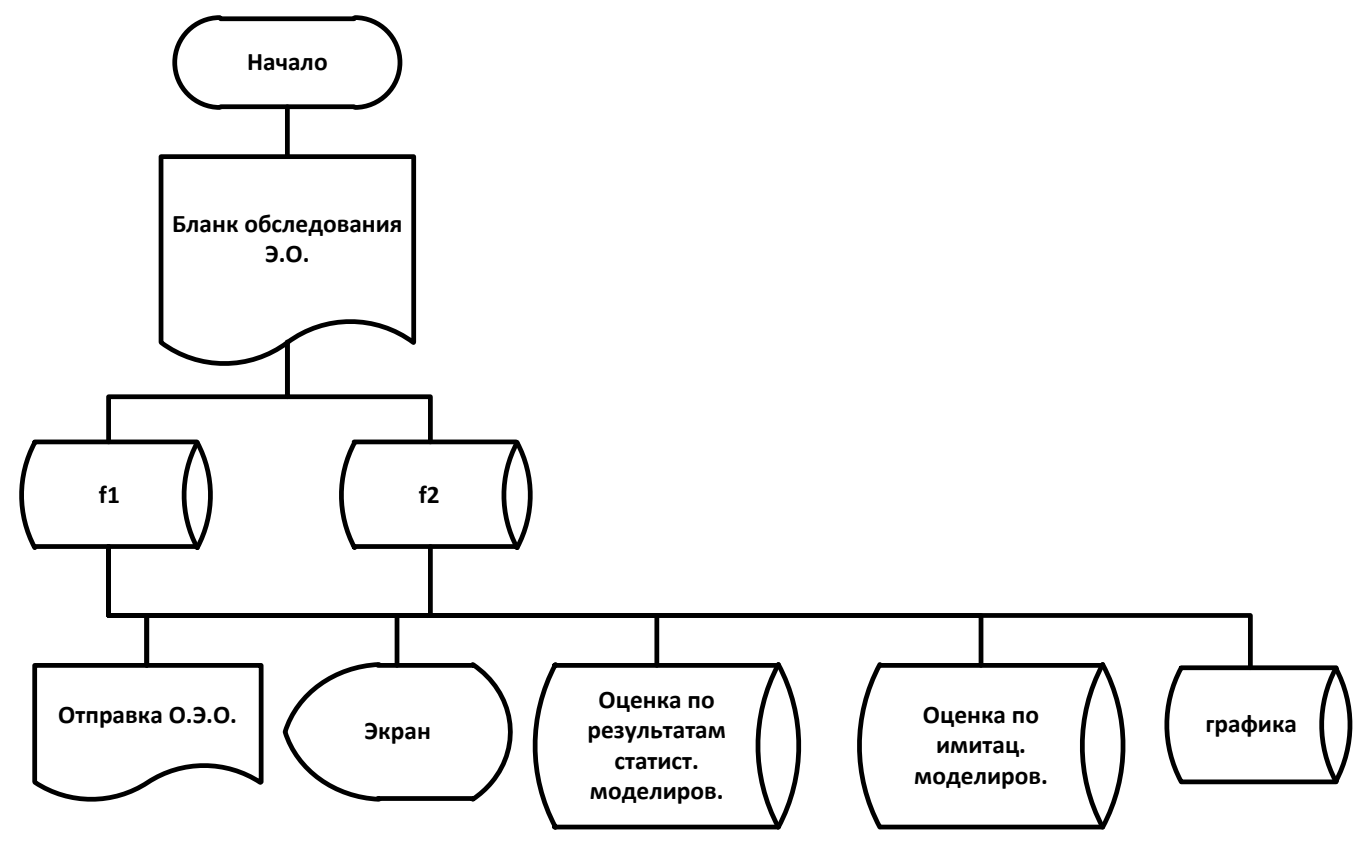

Рисунок 6. Схема данных СДКМС 
поддержка собственного поиска наиболее часто повторяемых документов, что позволяет квалифицированно подготовиться по любому вопросу, связанному с ЭО.

Характеристики Системы - консалтинг общего типа

- Полнота охвата;
- Возможность обновления информации;

- Широкие поисковые возможности;

- Подключение новых режимов;

- Работа в сетях;

- Сервисное обслуживание (обучение, сопровождение, доставка по листу внедрения, предоставление демо-варианта). 